DOI: http://dx.doi.org/10.22484/2177-5788.2016v42n1p51-67

\title{
A contribuição da literatura surda na ampliação dos conceitos de tradução e adaptação
}

\author{
Adriana Baptista de Souza \\ Maria Paula Frota
}

Resumo: Traduções, adaptações, criações. Assim podemos classificar as obras que compõem a literatura surda, conceito muito recente, já que, embora a existência dos surdos, de suas práticas sociais e formas de comunicação seja tão antiga quanto a humanidade, apenas na década de 1980 os estudos surdos começaram a acontecer no Brasil e apenas em 2002 a língua brasileira de sinais (Libras) foi oficialmente reconhecida como língua pelas leis brasileiras. Por isso ainda são escassos os estudos acadêmicocientíficos nacionais sobre a Libras, as culturas surdas brasileiras, seus costumes e produções, entre eles a prática de contar histórias. Essa prática faz parte da tradição surda, como ocorre em qualquer comunidade, mas não contava com os registros e a sistematização que hoje vêm se desenvolvendo no meio científico. Considerando as peculiaridades da literatura surda — conjunto de narrativas em línguas de sinais que incorporam elementos da cultura surda, como define Karnopp (2008; 2010), e, mais do que isso, conjunto de obras literárias bilíngues, sejam elas criadas, traduzidas e/ou adaptadas, em versão impressa ou em vídeo - argumentamos a favor da presença de seus estudos nos campos dos estudos da tradução e da adaptação, convencidas que estamos do potencial de enriquecimento mútuo dessas práticas e suas pesquisas.

Palavras-chave: Literatura surda. Tradução. Adaptação.

\section{The contribution of deaf literature in the expansion of the concepts of translation and adaptation}

Abstract: Translations, adaptations, creations. This is how we can classify the works that make up deaf literature, a very recent concept, since, although the existence of the deaf, their social practices and forms of communication is as old as humanity, it was only in the 1980s that the deaf studies began to happen in Brazil and only in 2002 that the Brazilian sign language (Libras) was officially recognized as a language by Brazilian law. That is why national academic-scientific studies on Libras, Brazilian deaf cultures, customs and their productions, including the practice of storytelling, are scarce. This practice is part of the deaf tradition, as in any community, but they did not have the records and systematization that is being developed today in the scientific community. Considering the peculiarities of deaf literature set of narratives in sign languages that incorporate elements of deaf culture, as defined by Karnopp $(2008 ; 2010)$, and, more than that, a set of bilingual literary works, whether they are created, translated and/or adapted, in print or video - we argue in favor of the presence of these studies in the fields of translation and adaptation studies, convinced that these practices and their research have a potential for mutual enrichment.

Keywords: Deaf literature. Translation. Adaptation. 
SOUZA, Adriana Baptista de; FROTA, Maria Paula. A contribuição da literatura surda na ampliação dos conceitos de tradução e adaptação.

\section{Introdução}

O presente texto é resultado da comunicação oral de mesmo título apresentada na I Jornada de Tradução e Adaptação (JOTA), realizada em novembro de 2015 na Universidade de São Paulo. Ele insere-se no desenvolvimento, ainda inicial, da pesquisa de doutorado de Adriana Baptista de Souza, orientada pela professora Maria Paula Frota, a qual, coautora deste trabalho, vincula-se aos estudos da tradução.

Adriana é professora de inglês da Secretaria Municipal de Educação do Rio de Janeiro e recentemente despertou para uma tendência cada vez mais presente nessa rede de ensino: a educação inclusiva. Mestre em Linguística e doutoranda em Estudos da Linguagem, interessouse por investigar academicamente um tipo de diversidade funcional estritamente relacionado à sua área, a surdez, no âmbito do contexto educacional inclusivo em que se insere profissionalmente.

Em seu processo de familiarização com a língua brasileira de sinais (Libras ${ }^{1}$ ) e os estudos surdos de modo geral, Adriana vem se dando conta de vários caminhos interessantes e ainda carentes de pesquisas. Seguir pelo caminho da literatura surda pareceu-lhe extremamente relevante, em particular quando se tem em vista o tema do evento supracitado - tradução e adaptação - já que a literatura surda se articula muito fortemente a essas duas práticas.

Ambas as autoras estão dando os primeiros passos no universo surdo e têm como motivação central para esta investigação, além do desejo de aprender, o desejo de contribuir para a importante difusão dos assuntos relacionados à cultura surda. É assim que, naquele evento e com este texto, dirigimo-nos especialmente aos estudiosos da tradução e da adaptação. O campo dos estudos da tradução (embora historicamente tenha abrigado estudos voltados para a língua brasileira de sinais, em particular no que tange à interação feita por tradutoresintérpretes entre essa nossa língua de sinais e nossa língua oral portuguesa) constitui-se como um campo tão amplo e diversificado que aqueles que o frequentam acabam, não raro, por restringir-se a um determinado território, razão pela qual desconhecem, por mais ricos e relevantes que sejam, experiências e estudos de vizinhos seus. Temos vivenciado com

\footnotetext{
${ }^{1}$ Usaremos inicial maiúscula por ser a forma mais comumente utilizada entre os estudiosos da área.
} 
SOUZA, Adriana Baptista de; FROTA, Maria Paula. A contribuição da literatura surda na ampliação dos conceitos de tradução e adaptação.

maravilhamento alguns primeiros encontros com alguns lugares do mundo dos surdos e é esse sentimento que nos faz ousar apresentar um pouco do pouco que conhecemos.

\title{
Literatura surda
}

Os surdos, em sua maioria, são sujeitos bilíngues, pois transitam em comunidades surdas e ouvintes, utilizando a língua de sinais e a língua oral nacionais nas interações que vivenciam em cada meio. Contar histórias é uma tradição de qualquer comunidade linguística, e não é diferente nas comunidades surdas, entre elas as brasileiras. Os surdos contam suas próprias histórias — piadas e anedotas, contos de fadas e fábulas, poemas, entre outras narrativas —, bem como histórias de que tomam conhecimento em outras comunidades, passando-as de geração em geração através de suas línguas de sinais.

Por muito tempo, as histórias (re)contadas nas comunidades surdas permaneceram apenas nas memórias, tal como ocorre em sociedades ágrafas. Como escreveu Karnopp (2008, s. p.): "a literatura surda tem uma tradição diferente, próxima a culturas que transmitem suas histórias oral e presencialmente”. Essa situação mudou nas últimas décadas, graças aos avanços tecnológicos (VHS, CD, DVD) e, no Brasil, principalmente a partir de 2002, com o reconhecimento da Libras como língua.

\begin{abstract}
A noção de Literatura Surda surgiu em alguns países da Europa e nos Estados Unidos, principalmente onde havia escolas de surdos. $\mathrm{Na}$ Universidade de Gallaudet (Gallaudet University), em Washington D.C., com o passar dos anos, os sujeitos surdos, acadêmicos e pesquisadores começaram a dar sentido à Literatura Surda, espalhando-as para seus próximos, na comunidade surda, como nos encontros de surdos, escolas de surdos, associação de surdos, etc. Alguns alunos surdos estrangeiros formados na Universidade de Gallaudet voltaram para seus países, divulgando conceitos para a comunidade surda local. Os acadêmicos e pesquisadores começaram a divulgar materiais empíricos, fazendo distribuição de livros, vídeos, etc. de fontes da Literatura Surda. (MOURÃO, 2011, p. 1-2)
\end{abstract}

Se por um lado pode ser limitador o gesto de definir literatura surda, diante da complexidade desse sistema literário que envolve uma minoria linguística e suas especificidades culturais, por outro lado, esse mesmo gesto contribui para o fortalecimento das bases científicas dos estudos surdos e suas ramificações, bem como para a divulgação desse campo na academia. 
SOUZA, Adriana Baptista de; FROTA, Maria Paula. A contribuição da literatura surda na ampliação dos conceitos de tradução e adaptação.

A literatura surda é constituída por histórias (re)contadas por surdos em línguas de sinais, através de processos de criação, tradução e/ou adaptação, como forma de expressão das culturas surdas. Ela constrói, altera e sedimenta identidades surdas no âmbito das próprias comunidades surdas e promove o seu conhecimento fora delas, tornando-se, assim, essencial na educação, não apenas de surdos, como também de ouvintes.

\section{Literatura surda e tradução}

O processo de (re)contar histórias envolve, necessariamente, atos de tradução e/ou adaptação. Quando um surdo aprende uma história em uma comunidade ouvinte — Cinderela, por exemplo - , e a reconta em língua de sinais na sua comunidade, ele a traduz de uma língua para outra, fazendo, claro, as transformações inevitáveis, impostas, para dizer o mínimo, pelas marcantes diferenças entre uma língua oral-auditiva, como o português, e uma língua visualespacial, como a Libras. Esse surdo pode também fazer transformações mais acentuadas no texto de partida, se quiser trazer, para a história sinalizada, elementos culturais do novo público; nesse caso ele faz uma adaptação. Pode, como é fato, transformar a personagem Cinderela numa princesa surda, e deixar isso claro já no título do conto, que passa a ser Cinderela Surda.

Gostamos de considerar, como o faz Mourão (2011), sem pretensões a uma classificação definitiva, que em meio às produções literárias surdas podemos identificar, como já indicado, traduções, adaptações e criações. Exemplos do primeiro caso seriam as traduções para Libras de clássicos estrangeiros e brasileiros, como Alice no País das Maravilhas e Iracema. Quanto às adaptações surdas, são comuns as que partem de histórias infantis, Patinho Surdo, por exemplo, ou de contos de fadas, como o mencionado Cinderela. Na literatura surda há também histórias criadas, ou seja, "textos originais que surgem e são produzidos a partir de um movimento de histórias, de ideias que circulam na comunidade surda" (MOURÃO, 2011, p. 4), como, por exemplo, segundo Silveira (2003), Tibi e Joca - uma história de dois mundos (2001), que conta como Tibi e seu amigo Joca, que é surdo, descobrem, juntos, algo que mudará a vida de Joca e sua família.

No que tange ao campo evidentemente complexo e multidisciplinar dos estudos surdos, existe, apesar de sua importante produção, uma escassez de pesquisas, e de divulgação dessas pesquisas, que acarreta uma desinformação generalizada acerca dos mundos surdos. Por esse 
SOUZA, Adriana Baptista de; FROTA, Maria Paula. A contribuição da literatura surda na ampliação dos conceitos de tradução e adaptação.

motivo e com o intuito de possibilitar aos leitores uma boa compreensão dos diversos casos de literatura surda que serão apresentados, julgamos interessante trazer nosso entendimento de alguns termos e conceitos, tendo em vista peculiaridades das línguas de sinais e seus entrelaçamentos com diferentes modalidades de tradução oral/sinalizada ou escrita. Argumentamos que a literatura surda amplia ainda mais noções e atividades tradutórias já bastante complexas e amplas, como é o caso da tradução oral/sinalizada que tradicionalmente denominamos interpretação (simultânea ou consecutiva), ou dos usos do termo adaptação em referência a obras derivadas de obras anteriores, adaptadas a um novo público e/ou a uma nova mídia (por exemplo, um romance clássico reescrito em versão infanto-juvenil e/ou em quadrinhos ou em versão cinematográfica).

A literatura surda - com seu papel de "difusão da cultura surda, dando visibilidade às expressões linguísticas e artísticas advindas da experiência visual” (KARNOPP, 2010, p. 165) - caracteriza-se, essencialmente, por ser um conjunto de obras que, como se viu, podem ser concebidas como traduções, adaptações ou criações literárias, todas elas em língua de sinais, seja na sua modalidade sinalizada ou escrita. Possuem, tipicamente, elementos da identidade surda para fins de reconhecimento e pertencimento à cultura surda, ou seja, são "histórias que têm a língua de sinais, a identidade e a cultura surda presentes na narrativa" (p. 161).

Por meio de um levantamento realizado na internet, foram selecionadas sete histórias que compõem a literatura surda brasileira, as quais, a nosso ver, constituem exemplos muito esclarecedores para os leigos e para os recém-ingressos no campo. Selecionamos três narrativas registradas graficamente em meio impresso (Os Três Porquinhos, Cinderela Surda e Rapunzel Surda) e quatro narrativas sinalizadas em vídeo (Branca de Neve, A Arara e o Macaco, Pinóquio e Turma da Mônica Jovem). Parte dessas produções aparece em outros trabalhos, como Karnopp (2008) e Mourão (2011), mas com enfoques um tanto distintos. O nosso interesse é muito mais o de analisar seus aspectos linguístico-tradutórios, tendo como referência diferentes movimentos interlinguísticos e intersemióticos, e não focar em aspectos fílmicos (como cenário, figurino, iluminação etc.) ou analisar personagens e enredos do ponto de vista das identidades surdas que as constituíram ou que elas (re)constroem.

Há uma riqueza linguística marcante nas produções literárias surdas, na medida em que nelas convivem ou podem conviver diferentes línguas e/ou modalidades linguísticas. Nas 
SOUZA, Adriana Baptista de; FROTA, Maria Paula. A contribuição da literatura surda na ampliação dos conceitos de tradução e adaptação.

brasileiras, por exemplo, podem estar presentes a Libras sinalizada; a modalidade escrita das línguas de sinais, muito referida como sign writing; um outro tipo de registro "escrito" que são os sinais desenhados; e a língua portuguesa, entre outras formas de linguagem gestual-visual ou oral-auditiva e seus registros gráficos. Mais comuns, as narrativas sinalizadas em vídeo, como se verá, têm como elemento central uma pessoa que narra a história em língua de sinais. Chama atenção, insistimos, a variedade de elementos (visuais) que convivem em tais narrativas surdas, sejam elas predominantemente feitas com sinais, gestos e expressões faciais, ou predominantemente escritas, isto é, com palavras, sinais, desenhos e ilustrações impressos em papel.

Seguindo numa análise ainda genérica dessa literatura, com um enfoque linguístico, pode-se então destacar a existência de produções monolíngues e de produções bilíngues. As primeiras são totalmente sinalizadas, ou seja, direcionadas especialmente para os surdos; tratase de vídeos que, sem legenda em português, são incompreensíveis para ouvintes sem conhecimento de Libras. Já as produções bilíngues, grande parte do sistema literário surdo contemporâneo, são aquelas que, como as narrativas sinalizadas em vídeo, trazem também legendas em língua oral; ou aquelas que, em papel, são escritas, por exemplo, em português e em Libras.

Insistimos em ressaltar, dirigindo-nos aos leigos, que pretender conhecer uma cultura surda implica abordar questões relacionadas às línguas de sinais bem como situações de tradução ou interpretação que envolvem línguas de sinais distintas ou, o que nos parece bem mais frequente, a coexistência de uma língua de sinais e uma língua oral, como nos casos de vídeos legendados ou de textos falados/escritos que venham a ser interpretados/reescritos em língua de sinais. Caberia também ressaltar a nossos leitores características das línguas de sinais e das línguas orais que as aproximam ou distanciam: ambas são constituídas por elementos verbais (as palavras, no caso das línguas orais, e os sinais, no caso das línguas de sinais) e não verbais (expressões faciais, corporais e gestos, por exemplo); se as línguas dos surdos e as línguas dos ouvintes são mutuamente estrangeiras, isso se dá porque as línguas de sinais apresentam-se na modalidade espaço-motora-visual, enquanto as línguas (literalmente) faladas apresentam-se na modalidade oral-auditiva; e por fim, também explicitamos que, se no âmbito 
SOUZA, Adriana Baptista de; FROTA, Maria Paula. A contribuição da literatura surda na ampliação dos conceitos de tradução e adaptação.

das línguas orais, costumamos nos referir a textos falados ou escritos, em se tratando das línguas de sinais, faz-se referência a textos sinalizados ou em escrita de sinais.

Para encerrarmos esta seção que articula textos surdos e tradução (termo aí usado no sentido amplo que abarca interpretação e adaptação), julgamos que cabe trazer, também neste caso de convivência entre línguas de sinais e línguas orais, a classificação de Roman Jakobson ([1959]1975). Fazemos questão de trazê-la seguindo o movimento de retomada transformadora que foi liderado, a partir do final da década de 1980, com a popularização do VHS, pelos estudiosos da tradução audiovisual (FRANCO; ARAUJO, 2011, p. 1). Interessados nas modalidades de tradução, historicamente mais recentes, como a legendagem e a dublagem, a legendagem para surdos e ensurdecidos, a audiodescrição, assim como a interpretação de/para línguas de sinais, tais estudiosos ampliaram e atualizaram a classificação de Jakobson de modo a poderem desenvolver estudos focados nas especificidades desses novos atos tradutórios.

Como propôs o linguista, em meados do século XX, a tradução interlingual ou tradução propriamente dita "consiste na interpretação dos signos verbais por meio de alguma outra língua" (JAKOBSON, 1975, p. 65). A tradução intralingual consiste na "interpretação dos signos verbais por meio de outros signos da mesma língua" (p. 64), comumente associada a adaptações de histórias para um público-alvo diferente daquele ao qual se dirige o original. Já a tradução intersemiótica é definida pelo autor como uma "interpretação dos signos verbais por meio de sistemas de signos não verbais" (p. 65), comumente associada a adaptações de livros para o teatro ou cinema. Cabe deixar claro que esses três tipos de tradução não ocorrem isoladamente; com muita frequência, as traduções são simultaneamente interlinguais e intersemióticas ou intralinguais e intersemióticas.

Valendo-nos da classificação de Jakobson, procuramos sistematizar algumas situações de tradução envolvendo línguas orais e de sinais. Uma seria a tradução interlingual que se realiza ao vivo, por um intérprete, de um texto em uma língua oral para um texto em uma língua de sinais, e vice-versa. Uma segunda situação de tradução interlingual se distinguiria da anterior apenas por se realizar não na modalidade oralidade-sinalização mas na modalidade escrita, ou seja, consistiria em uma reescrita de um texto em língua oral de/para um texto escrito em uma língua de sinais. Uma terceira situação consistiria em uma tradução intralingual, isto é, um texto sinalizado é traduzido para a modalidade escrita dessa mesma língua de sinais, ou vice-versa, 
SOUZA, Adriana Baptista de; FROTA, Maria Paula. A contribuição da literatura surda na ampliação dos conceitos de tradução e adaptação.

da modalidade escrita para a sinalizada. Por fim, mas não menos importante, consideremos que algumas dessas situações tradutórias envolvem (ou podem envolver) maior complexidade, na medida em que, para além de se darem entre línguas distintas ou entre modalidades linguísticas distintas, elas envolvem mudança de mídia, caracterizando-se, também, como traduções intersemióticas - é o caso, bastante comum, de vídeos que são produzidos a partir de livros, em outras palavras, de vídeos que traduzem textos escritos.

\section{Literatura surda impressa}

A literatura surda impressa será aqui ilustrada por breves excertos de três produções surdas, traduzidas e/ou adaptadas com base em histórias infantis bem conhecidas: Os Três Porquinhos, Cinderela Surda e Rapunzel Surda.

A versão de Os Três Porquinhos (figura 1) que analisamos apresenta a história escrita em língua portuguesa, seguida da sua tradução para a Libras, sendo esta graficamente registrada, através de desenhos dos sinais. Podemos dizer que essa narrativa configura, assim, uma tradução interlingual, nos termos de Jakobson apresentados anteriormente. Além disso, a obra conta com ilustrações que se posicionam cada qual à esquerda ou à direita do respectivo texto verbal, em certa medida traduzindo-o imageticamente, o que traz ao conjunto da obra a modalidade intersemiótica de tradução. 
Figura 1 - Os Três Porquinhos

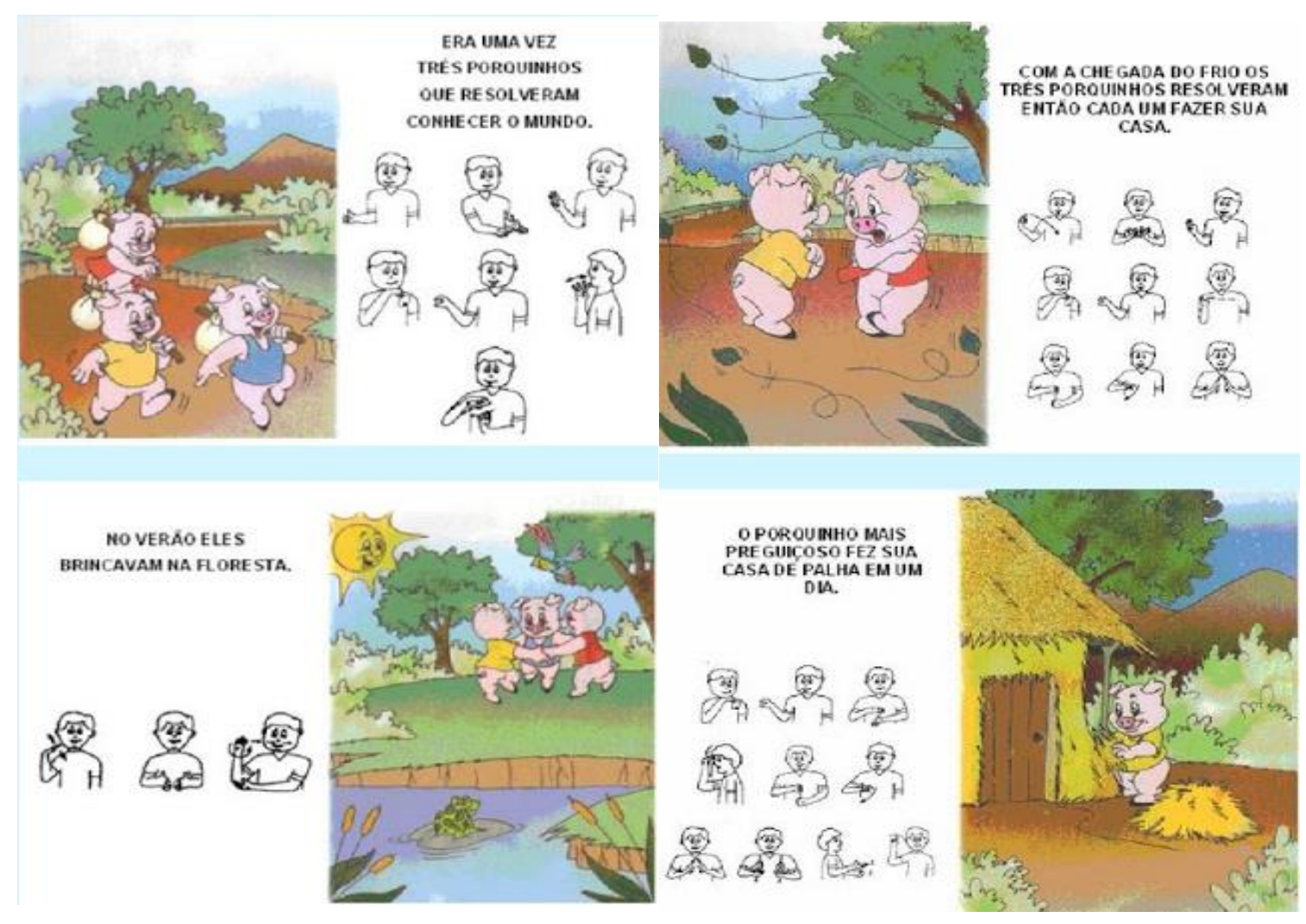

Fonte: Os Três Porquinhos. Disponível em: <http://ensinar-aprender.com.br/2011/05/historia-dos-3-porquinhosem-Libras.html>. Acesso em: 5 fev. 2016.

Embora estejamos integrando a narrativa acima ao sistema literário surdo, cabe dizer que há quem defenda, como Karnopp (2010, p. 172), que narrativas como essa "referem o uso da língua de sinais, mas descontextualizado do pertencimento a uma comunidade de surdos". Contudo, como nossa motivação é valorizar cada passo dado na produção cultural surda e nos estudos surdos, a estamos vendo como uma produção legítima em língua de sinais e, consequentemente, integrante do conjunto de narrativas que compõem o sistema literário surdo.

Por outro lado, sem dúvida concordamos que os livros Cinderela Surda e Rapunzel Surda (figura 2), conforme veremos abaixo, são exemplos de obras mais engajadas e representativas da literatura surda, na medida em que, como argumenta a mesma estudiosa, elas "focalizam o uso da língua de sinais por pessoas surdas, o pertencimento cultural, a questão da 
SOUZA, Adriana Baptista de; FROTA, Maria Paula. A contribuição da literatura surda na ampliação dos conceitos de tradução e adaptação.

identidade e da cultura surda, presentes nos textos e/ou nas imagens" (KARNOPP, 2010, p. 172).

\section{Figura 2 - Cinderela Surda e Rapunzel Surda}

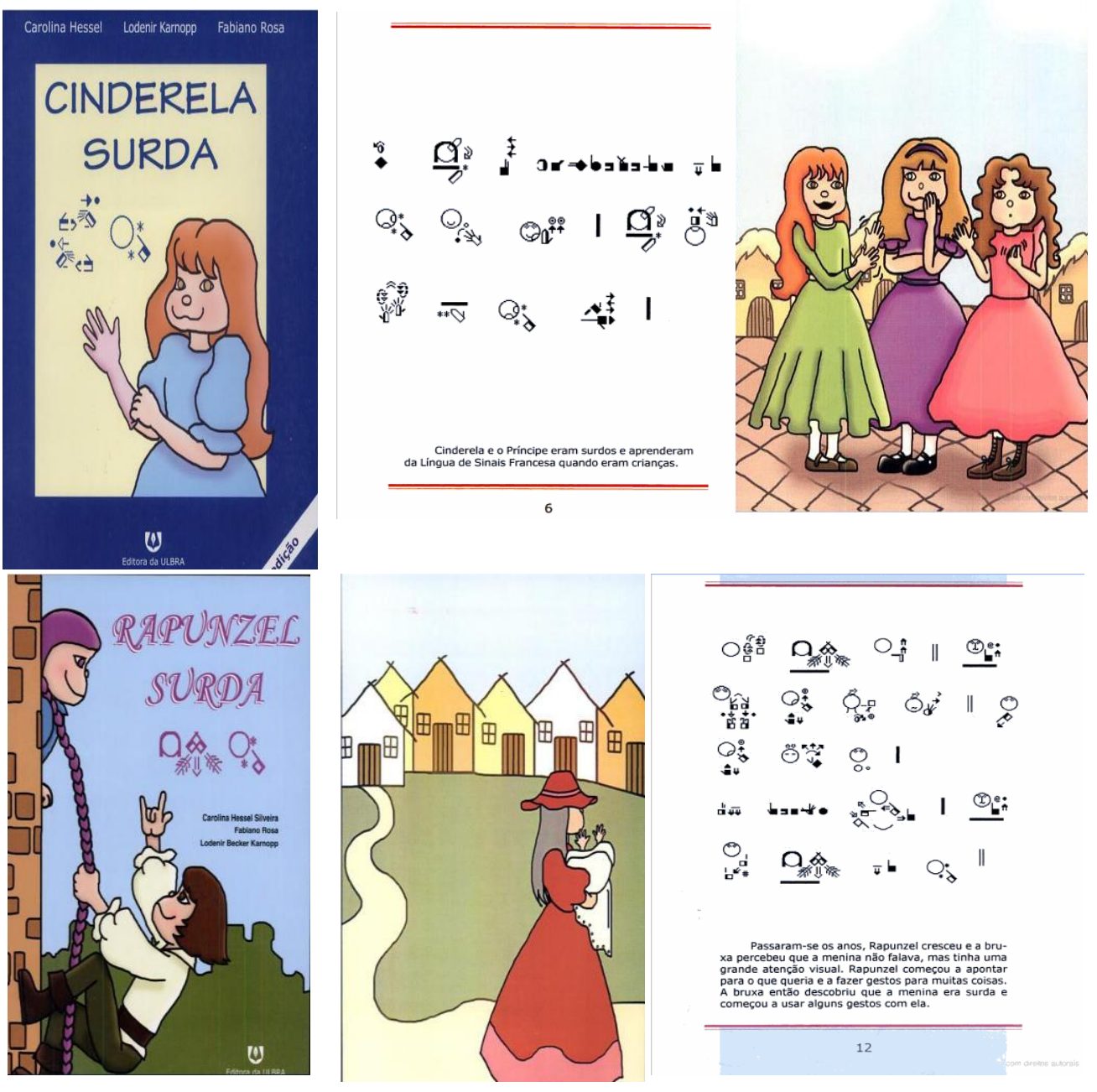

Fonte: Cinderela surda e Rapunzel surda. Disponível em:

<https://escritadesinais.wordpress.com/2010/08/30/cinderela\%C2\%A0surda-e-rapunzel-surda/>. Acesso em: 5 fev. 2016.

Os livros acima são adaptações, para o público surdo, de histórias infantis conhecidas nas comunidades ouvintes. Caracterizam-se portanto como adaptações e também como traduções interlinguais, na medida em que são textos (re)escritos em escrita de sinais e traduzidos para a língua portuguesa. Não só o material textual escrito como também as 
SOUZA, Adriana Baptista de; FROTA, Maria Paula. A contribuição da literatura surda na ampliação dos conceitos de tradução e adaptação.

ilustrações que o acompanham apresentam traços de adaptação cultural, fortalecendo a ideia do pertencimento de que trata Karnopp (2010): em Cinderela Surda a imagem da luvinha na capa do livro simboliza a centralidade das mãos nessa adaptação da história; como indica o texto escrito, Cinderela e o príncipe, ambos surdos, conseguem manter uma comunicação através da língua de sinais; por fim, Cinderela é retratada sinalizando na ilustração que acompanha o texto.

Rapunzel Surda também se constitui como uma adaptação cultural, tanto nas imagens quanto no texto escrito: a capa do livro retrata o príncipe sinalizando para Rapunzel e na ilustração que acompanha o texto as mãos de Rapunzel, que acabara de nascer, têm destaque na imagem. Segundo o texto escrito, ela nasceu surda e a imagem reforça a utilização dos gestos pela criança surda desde bebê. Parece clara, nos dois casos, a preponderância da perspectiva surda.

\section{Literatura surda em vídeo}

A literatura surda em vídeo apresenta grandes variações em termos de narração, animação, ilustração e legenda, como veremos em quatro situações distintas abaixo.

O primeiro vídeo consiste em uma adaptação em Libras da Branca de Neve (figura 3), com legenda traduzida para a língua portuguesa e cenários que vão mudando ao longo da história. É a própria personagem, inserida nos cenários, que narra a história em Libras, sem explicitar se é surda e sem outras evidências de adaptação cultural, como ocorre em Cinderela Surda e Rapunzel Surda, por exemplo. Enxergamos aí, bem evidentes, pelo menos dois movimentos tradutórios: a tradução intersemiótica, considerada a transposição da versão tradicionalmente impressa em papel para um meio dinâmico audiovisual; e a tradução interlingual, sob a forma de legenda. 
SOUZA, Adriana Baptista de; FROTA, Maria Paula. A contribuição da literatura surda na ampliação dos conceitos de tradução e adaptação.

\section{Figura 3 - Branca de Neve}

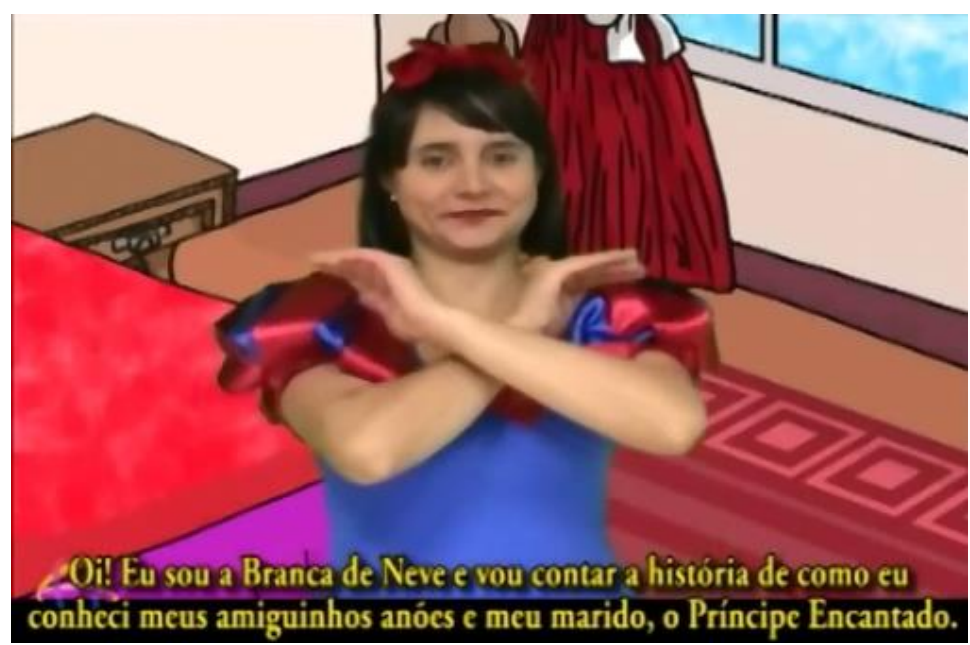

Fonte: Branca de Neve. Disponível: em: <https://www.youtube.com/watch?v=3nztiJSc7vo>. Acesso em: 5 fev. 2016.

O segundo vídeo, abaixo, apresenta alguns pontos convergentes e outros divergentes do vídeo anterior: ele também traz uma narração em Libras, mas, diferentemente da Branca de Neve, esta história é narrada em terceira pessoa; a narradora encontra-se fora dos cenários, que, assim como na Branca de Neve, vão mudando com o desenrolar da história. A Arara e o Macaco (figura 4), assim como a história de Tibi e Joca mencionada logo ao início deste trabalho, é uma fábula criada pela comunidade surda e não traz legendas em língua portuguesa. Somando-se esses dois últimos aspectos, pode-se dizer que se trata de uma produção criativa de surdos para surdos, a qual não envolve um processo tradutório propriamente dito. 


\section{Figura 4 - A Arara e o Macaco}

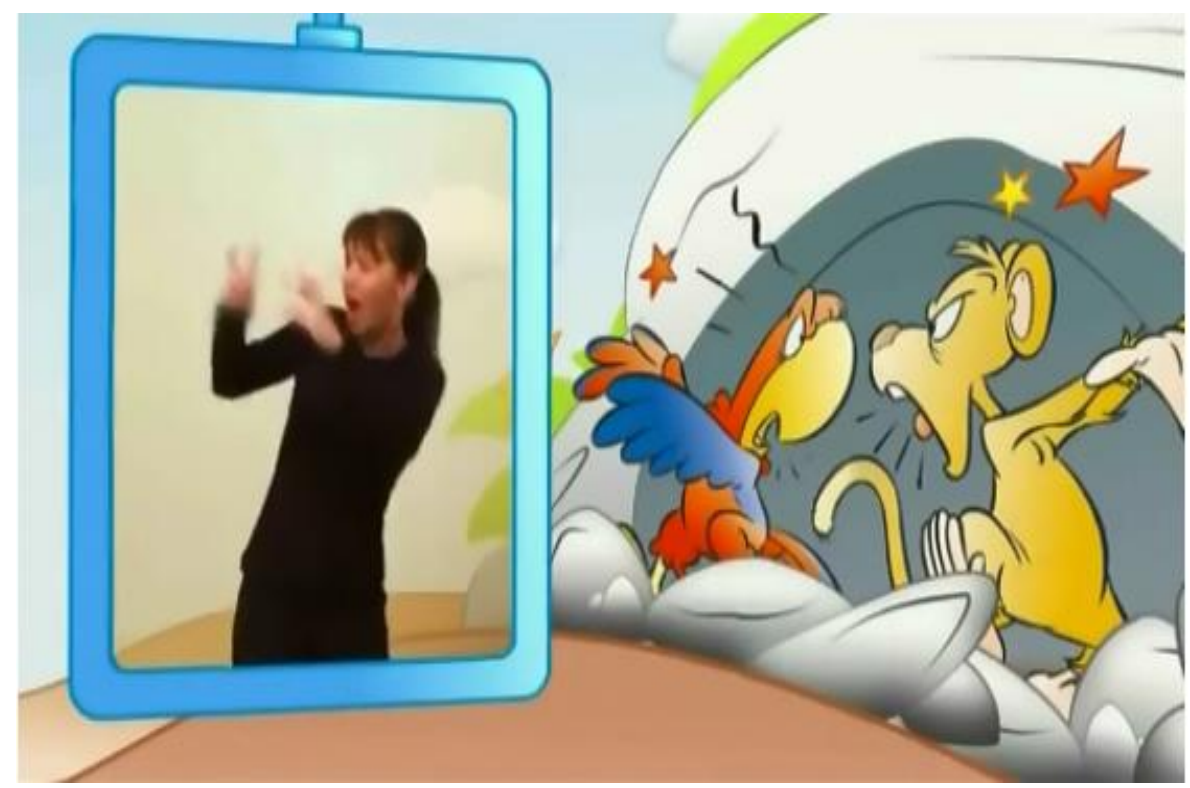

Fonte: A Arara e o Macaco. Disponível em: 〈https://www.youtube.com/watch?v=z2p8x8_4Reg>. Acesso em: 5 fev. 2016.

O terceiro vídeo é uma tradução interlingual para Libras da história Pinóquio (figura 5). Sem cenários, o narrador sinaliza a história em terceira pessoa. O vídeo conta com legendas que se utilizam de palavras em língua portuguesa, mas, de modo muito significativo, essas legendas apresentam-se na estrutura da Libras, configurando-se, assim, como um processo análogo ao que se convencionou chamar de "tradução palavra-por-palavra". Ou seja, não são feitas, no texto de chegada, as transformações linguísticas que de um modo geral estão implicadas em um ato tradutório que envolve duas línguas diferentes. 
SOUZA, Adriana Baptista de; FROTA, Maria Paula. A contribuição da literatura surda na ampliação dos conceitos de tradução e adaptação.

\section{Figura 5 - Pinóquio}

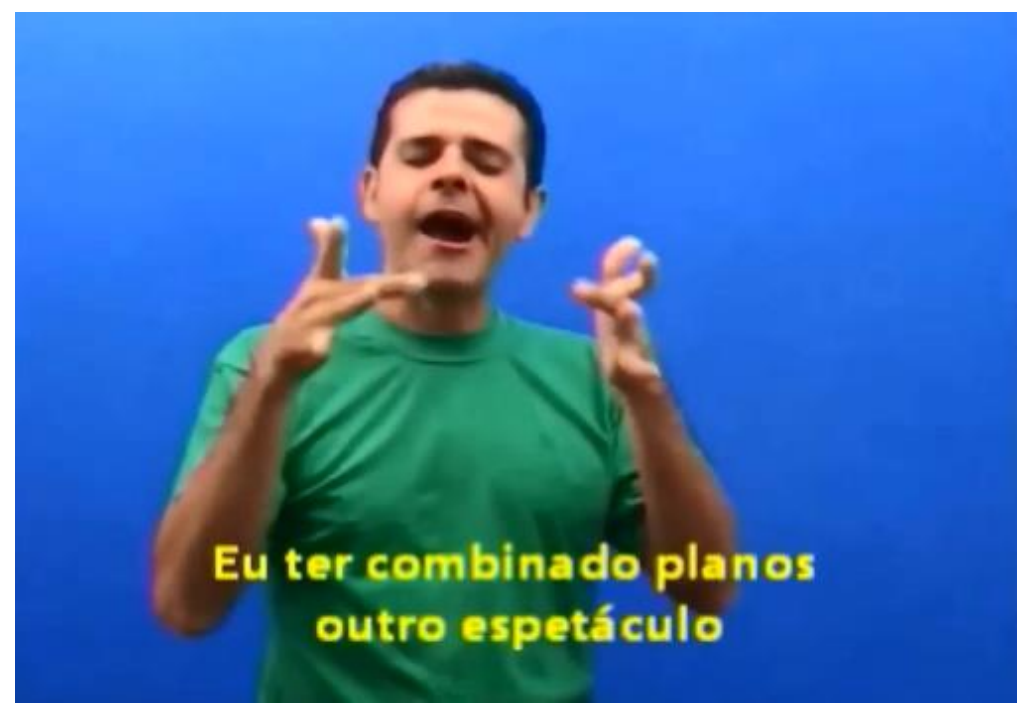

Fonte: Pinóquio. Disponível em: 〈https://www.youtube.com/watch?v=C7UegznsZ_w〉. Acesso em: 5 fev. 2016.

O quarto vídeo é uma tradução intersemiótica e interlingual da Turma da Mônica Jovem (figura 6), revista em quadrinhos que conta com texto verbal e imagético, traduzidos, em forma de janela de Libras, que acompanha a exibição das páginas da revista com texto em língua portuguesa.

Figura 6 - Turma da Mônica Jovem

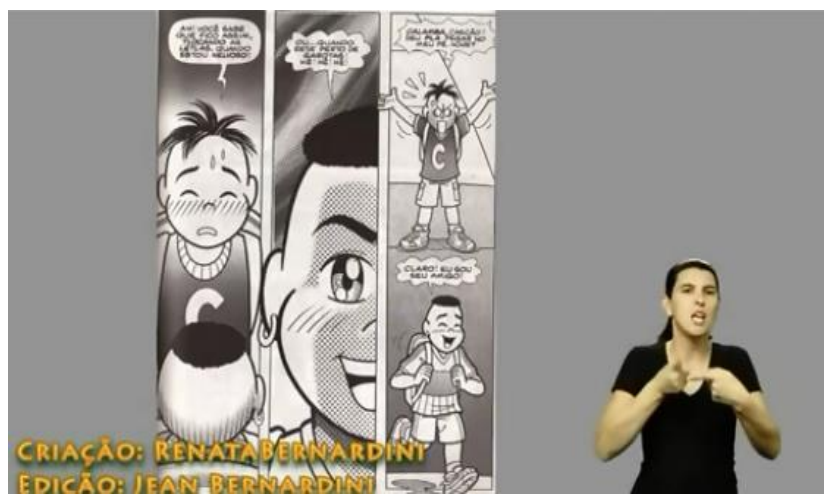

Fonte: Turma da Mônica Jovem. Disponível em: 〈https://www.youtube.com/watch?v=C13z14AlszI>. Acesso em 5 fev. 2016. 
SOUZA, Adriana Baptista de; FROTA, Maria Paula. A contribuição da literatura surda na ampliação dos conceitos de tradução e adaptação.

\section{Breves comentários gerais sobre os casos}

Como se procurou mostrar com os sete casos acima, a literatura surda pode se manifestar de diversas formas e em diversas mídias: no meio impresso (papel) pode se dar, como indicado, por meio da escrita de sinais - que não é muito comum devido ao fato de esta ainda estar em fase de expansão - ou por meio dos sinais em forma de desenhos, o que também não é muito comum, talvez por não contemplar alguns aspectos importantes como movimentos do corpo e expressões faciais, por exemplo. Já as produções literárias surdas em vídeo apresentam grande variedade e tendem a ser bilíngues, com legendas em língua portuguesa, muito provavelmente por causa de sua significativa importância no letramento de surdos e na sensibilização dos ouvintes. Dentre as produções que foram analisadas neste artigo, a única produção surda monolíngue, acompanhada apenas de ilustrações, consiste em um tipo de produção que estamos, com outros autores, considerando uma criação. Caberia um estudo sobre esse tipo de obra a fim de investigar se essas criações surdas são majoritariamente monolíngues e quais os impactos disso nas comunidades surdas e ouvintes do país.

Voltamos então a dizer que o sistema literário surdo parece constituído por produções que, como ilustram as sete narrativas analisadas, são caracterizáveis como tipicamente criações, adaptações ou traduções, fazendo-se a ressalva de que não há limites sempre nítidos e absolutos entre essas formas textuais.

Há que se ressaltar ainda os variados gêneros dessa literatura: além de termos aqui ilustrado gêneros como contos de fadas, fábulas e quadrinhos, há ainda inúmeros outros, como poemas, romances, piadas, etc., os quais não foram alvo de pesquisa neste momento. 
SOUZA, Adriana Baptista de; FROTA, Maria Paula. A contribuição da literatura surda na ampliação dos conceitos de tradução e adaptação.

\section{Considerações finais}

O presente artigo pretendeu apresentar um pouco da literatura surda, sobretudo para os colegas dos campos da tradução e da adaptação que porventura sejam, como estas autoras, iniciantes ou leigos no assunto. Pretendeu também enriquecer as reflexões sobre essas duas práticas, na medida em que a literatura surda, por envolver produções fundamentalmente constituídas por línguas de sinais, apresenta especificidades linguístico-culturais que impactam e renovam os processos de tradução e adaptação mais conhecidos. Efeitos de impacto e renovação equivalentes, em importância, àqueles que vêm sendo desencadeados pela audiodescrição de filmes e de outros produtos que, por sua natureza fortemente visual, são de acesso difícil ou impossível para pessoas com deficiência visual.

O imenso público que faz uso e desfruta, quase que ininterruptamente, das incontáveis obras traduzidas e adaptadas segundo as tradicionais modalidades dessas duas práticas de "reescrita", por ser um público de ouvintes em sua maior parte, não tem ainda consciência da amplitude dessas práticas. Seria muito bom que os ouvintes, ao menos no plano do conhecimento, se não da vivência, pudessem superar as fronteiras das línguas orais. Hoje, com o reconhecimento do status linguístico da Libras e os avanços tecnológicos que desencadearam as diversas possibilidades de registro das produções surdas, tem-se um número crescente de obras literárias surdas e pesquisas a respeito, o que evidencia a sua importância, seja no que concerne à educação dos surdos ou à conscientização dos ouvintes.

Há ainda muito a aprendermos sobre as produções das comunidades surdas e sobre os estudos das mesmas. As produções ficcionais surdas, além de narrativas impressas ou em vídeo como as que abordamos aqui, também se realizam sob outras tantas formas, como é o caso, por exemplo, dos poemas sinalizados e das dramatizações, os quais poderão ser objeto de trabalhos futuros.

\section{Referências}

FRANCO, Eliana P. C.; ARAÚJO, Vera S. Questões terminológico-conceituais no campo da tradução audiovisual (TAV). Tradução em Revista, Rio de Janeiro, v. 2, n. 11, p. 1-23, 2011.

JAKOBSON, Roman. Aspectos linguísticos da tradução. In: LINGUÍSTICA e comunicação. São Paulo: Cultrix, 1975. 
SOUZA, Adriana Baptista de; FROTA, Maria Paula. A contribuição da literatura surda na ampliação dos conceitos de tradução e adaptação.

KARNOPP, Lodenir. Literatura surda. Florianópolis: UFSC, 2008.

KARNOPP, Lodenir. Produções culturais de surdos: análise da literatura surda. Cadernos de Educação, Pelotas, p. 155-174, 2010.

MOURÃO, Cláudio H. N. Adaptação e tradução em literatura surda: a produção cultural surda em língua de sinais. Dissertação (Mestrado em Educação) - PPGE-UFRGS. Porto Alegre, 2011.

SILVEIRA, Rosa Maria H. Nas tramas da literatura infantil: olhares sobre personagens "diferentes". In: SEMINÁRIO INTERNACIONAL DE EDUCAÇÃO INTERCULTURAL: gênero e movimentos sociais, 2., Florianópolis, 2003.

Adriana Baptista de Souza - Pontifícia Universidade Católica do Rio de Janeiro | Rio de Janeiro | Rio de Janeiro. Contato: adribaptsouza@hotmail.com

Maria Paula Frota - Pontifícia Universidade Católica do Rio de Janeiro | Sorocaba | São Paulo. Contato: mpfrota@puc-rio.br

Artigo recebido em março de 2016 e aprovado em junho de 2016 